\title{
Preparation, Properties, and Crosslinking Studies on Polyurethane Elastomers
}

\author{
Harimurthi Kothandaraman, Krishnan VenKaTARAO, \\ and Bagavathikan Chithambara THANOO* \\ Department of Polymer Science, University of Madras, \\ Guindy Campus, Madras-600 025, India
}

(Received September 5, 1988)

\begin{abstract}
Polyurethane elastomers were prepared from structurally distinct hydroxyterminated polybutadiene and polyether-ester based prepolymers with diisocyanates such as hexamethylenediisocyanate, toluenediisocyanate, and diphenylmethanediisocyanate by the one short polymerization process. The effect of crosslinking by polyfunctional alcohols such as castor oil, trimethylolpropane, and poly(vinyl alcohol) on mechanical properties is compared in case of hydroxyterminated polybutadiene based polyurethane systems. The effect of crosslinking by trimethylolpropane on the mechanical properties was quantitatively studied in all the prepolymers based polyurethane systems. Crosslinking was also induced in the polyurethanes by taking higher $\mathrm{NCO} / \mathrm{OH}$ ratio ( $R$ value) and the observations on mechanical properties are compared with those prepared with trimethylolpropane crosslinking. The thermal degradation of the polymers was studied in an oxygen atmosphere and interpreted with respect to their structure.

KEY WORDS Polyurethane Elastomers / Crosslinked Polyurethanes /

NCO/OH Ratio Effect / HTPB Based Polyurethanes / Copolyetherester

Polyols /
\end{abstract}

Polyurethanes are prepared by reacting polyols with diisocyanates. The most commonly used polyols include low molecular weight hydroxyterminated polymers of saturated and unsaturated aliphatic hydrocarbon, polyethers and polyesters. The functionality of the hydroxyl containing compounds as well as isocyanates can be increased to three or more to form branched or crosslinked polymers. Other structural changes can also be made by changing the type and molecular weight of the intervening groups. Polyurethanes are unique in their crosslinking, chain flexibility and intermolecular forces which can be varied widely. The abundance of original substances used for preparing urethane elastomers in conjunction with the wide variety of reactions taking place during their synthetic cause the highly complicated chemical structure of the resulting polyurethanes. ${ }^{1-5}$ Crosslinking of polyurethanes is of primary importance in controlling many of their properties. ${ }^{6}$ The degree of crosslinking was controlled by the use of polyfunctional ingredients or by taking excess diisocyanate than that of the stoichiometric requirement. Crosslinking at higher diisocyanate ratio is reported to proceed through the formation of allophanate and isocyanurate linkages. ${ }^{7}$ A significant change in properties by crosslinking may also be expected in the case of elastomers like polyether based polyurethanes. $^{8-10}$ In the present study, polyurethane elastomers were prepared from four

* Present address: Division of Polymer Chemistry, Sree Chitra Tirunal Institute for Medical Sciences and Technology, Trivandrum-695 012, India. 
structurally different prepolymers and the effect of crosslinking on mechanical properties by both methods, i.e., by the use of polyfunctional alcohol and excess diisocyanate is compared.

\section{EXPERIMENTAL}

\section{Materials}

Hydroxyterminated polybutadiene (HTPB), ISRO Polyol, dimerized linoleic acid (dimer acid) obtained from Vikram Sarabhai Space Centre, Trivandrum, India, were dried under vacuum before subjected to polymerization. Poly(vinyl alcohol) [(PVA), Molecular weight (MW) 40,000 from BDH, England], trimethylolpropane [(TMP) from Fluka] and castor oil (Indian Pharmacopia, hydroxyl number 130 and carboxyl number 1.3) were dried before use. Hexamethylenediisocyanate [(HMDI) from Fluka] and diphenylmethane diisocyanate [(MDI) from Fluka] were purified by distillation under reduced pressure. Toluenediisocyanate [(TDI) $80 \% \quad 2,4$ and $20 \%$ 2,6 isomers from Fluka] was used as received. Tetrahydrofuran [(THF) from SD's, India, AR] was dried over sodium and distilled before use. Propylene oxide (AG, Fluka) and acetic anhydride (SD's, India, AR) were used as received.

\section{Preparation of Prepolymers Based on Dimer Acid} (Dimerized Linoleic Acid)

Copolyether-esters having terminal hydroxyl functions based on dimer acid (dimerized linoleic acid) were prepared by the reaction of low molecular weight poly(oxytetramethyleneglycol) (POTMG) and poly(oxytetramethylene-co-oxypropyleneglycol) (POTMOPG) with the dimer acid. Low molecular weight POTMG (MW: 540) was prepared by cationic ring opening polymerization of tetrahydrofuran (THF) in presence of excess of acetic anhydride and the subsequent hydrolysis of the acetate end. ${ }^{11,12}$ Poly(oxytetrameth- ylene-co-oxypropyleneglycol) (POTMOPG) having MW 620 was prepared by cationic ring opening polymerization of THF and propylene oxide with excess of 1,4-butanediol, the chain transfer agent. ${ }^{13}$ Linear polyesters with hydroxyl endcapping were best prepared by the polycondensation of these two glycols and the dimer acid taking excess glycol by the procedure of Brown et al. ${ }^{14}$ The polyesterification was carried out till the carboxyl number fallen below 1.0, which was estimated by the standard procedure. ${ }^{15}$ Thus poly(oxytetramethylene)dilinoleate (POTMDL) was prepared by the condensation of $0.9 \mathrm{~mol}$ of POTMG (MW 540) and $0.5 \mathrm{~mol}$ of dimer acid and poly(oxytetramethylene-co-oxypropylene)dilinoleate (POTMOPDL) was prepared by the condensation of $0.9 \mathrm{~mol}$ of POTMOPG (MW 620) and $0.5 \mathrm{ml}$ of dimer acid.

\section{Preparation of Polyurethane}

A reaction kettle fitted with a vacuum sealed stirrer and a nitrogen gas inlet was charged with the required amount of prepolymer under study. After degassing the prepolymer under vacuum, equivalent amount (based on the hydroxyl group) of HMDI, TDI, or MDI was added and mixed thoroughly by stirring. Dry nitrogen gas blanketing was maintained throughout the mixing. After $10 \mathrm{~min}$ of mixing, the highly viscous syrup was degassed under vacuum to produce clear, bubble free resin, and transferred into a tray (coated with silicone oil) to get a film of 2 to $4 \mathrm{~mm}$ thickness. The resin was cured in an air oven at 60 $65^{\circ} \mathrm{C}$ for 5 days. The crosslinked polyurethane elastomers were prepared using the desired concentration of the castor oil, TMP, or PVA with prepolymer. While using TMP or PVA as the crosslinking agent, the prepolymercrosslinking agent mixture was first heated to $50^{\circ} \mathrm{C}$ with stirring before degassing to ensure the homogeneous mixing of the crosslinking agent. Then diisocyanate was added and the polyurethane elastomer was cast as before. Polyurethane elastomers with various $R$ values 
([NCO]/[OH] ratio) were prepared by mixing the prepolymer with the calculated amount of TDI for desired [NCO]/[OH] value. The resulting syrup was cured at $80^{\circ} \mathrm{C}$ for 5 days to give the elastomer. The resulted elastomer was analyzed for the isocyanate content if any unreacted. ${ }^{16}$

\section{Characterization of Prepolymers}

The hydroxyl number of the prepolymers and castor oil were found out by acetylation method. ${ }^{17}$ The viscosity of the prepolymer was determined using the Brookfield-type viscometer (Brookfield Engineering Laboratories, Inc., U.S.A.) at $25^{\circ} \mathrm{C}$. The molecular weights of these prepolymers were calculated ${ }^{18}$ from the hydroxyl and carboxyl number.

\section{Characterization of Polyurethane}

Tensile strength, elongation at break and initial modulus of the cast polyurethane elastomers were measured using INSTRON Model 1122 (England) by the standard procedure $^{19}$ at the cross head speed of 20 $\mathrm{mm} \mathrm{min}^{-1}$ at $30^{\circ} \mathrm{C}$. Average of four values was taken. Thermal degradation (TGA) of the polyurethanes was carried out in a Mettler TA 3000 system in an oxygen atmosphere at a heating rate of $20 \mathrm{~K} \mathrm{~min}^{-1}$. The temperature at which the rate of decomposition was maximum $\left(T_{\max }\right)$ was obtained from the derivative curve of the weight change with time (DTG).

\section{RESULTS AND DISCUSSION}

The structures of the dimer acid, crosslinking agents (castor oil, TMP and PVA) and the prepolymers are given in Figure 1. Here, caster oil contains $70 \mathrm{~mol}^{\circ} \%$ of triol fraction and $30 \mathrm{~mol}^{\circ} \%$ of diol fraction. All the prepolymers are viscous liquids with the properties which is ideal to prepare polyurethane by reaction injection moulding (RIM) technique (Table I). These polyurethanes are prepared from these prepolymers by the one shot process with stoichiometric equivalent of the diisocyanate
(HMDI, TDI, and MDI) without chain extender. The completion of the polyurethane formation under curing at $80^{\circ} \mathrm{C}$ for 5 days was evidenced from the absence of unreacted isocyanate in the resulted elastomer. Mechanical properties showed that HMDI based polyurethanes are weak compared to that of TDI and MDI based ones (Table II). This may be due to the comparatively less reactivity of HMDI towards hydroxyl compounds ${ }^{20}$ and the less effective intermolecular interaction in the resulted polymer as the methylene group of HMDI is having very low molar cohesive energy $^{21}$ compared to the aromatic group of TDI and MDI. Among all the prepolymers ISRO polyol will form crosslinked polyurethanes as it is having hydroxyl functionality greater than two whereas all other prepolymers based polyurethanes will be linear.

The crosslinking efficiency of castor oil, TMP, and PVA was compared by preparing polyurethanes from HTPB with HMDI and TDI with these crosslinking agents keeping the ratio of the hydroxyl group content of the crosslinking agents to that HTPB as 0.5 (Table III). In all these cases, both hardness and tensile strength increased on crosslinking while elongation decreased as per the expectations. ${ }^{22}$ Even though same equivalent (as per the hydroxyl content) of the crosslinking agents was used, the increase in tensile strength with castor oil is not high compared to TMP and PVA. This may be explained ${ }^{23}$ as due to its low hydroxyl functionality of 2.7 compared to TMP having the value 3.0 and PVA with a very high value. Despite the low crosslinking efficiency of castor oil, it is preferred in cases where room temperature mixing is required, since as a liquid, it mixes well with almost all the prepolymers at room temperature. An added advantage of using castor oil as crosslinking agent is the higher potlife of the product formed. Crosslinking with TMP on the mechanical properties of the TDI cured polyurethanes was studied quantitatively (Table IV). The extent of crosslinking was varied by 
DIMER ACID

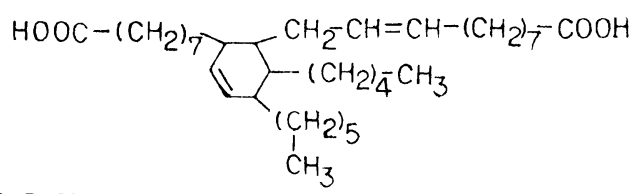

CASTOR OIL

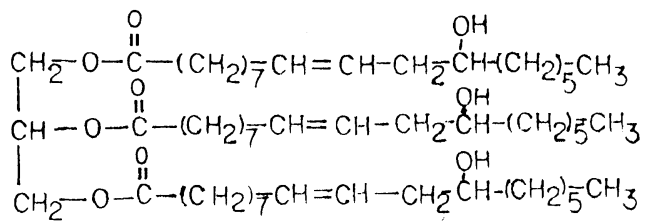<smiles>CCC(CO)(CO)CO</smiles>

PVA

$+\underset{\mathrm{OH}}{\mathrm{CH}}+\mathrm{H}_{\mathrm{H}}^{\mathrm{C}} \mathrm{H}+\frac{\pi}{n}=910$
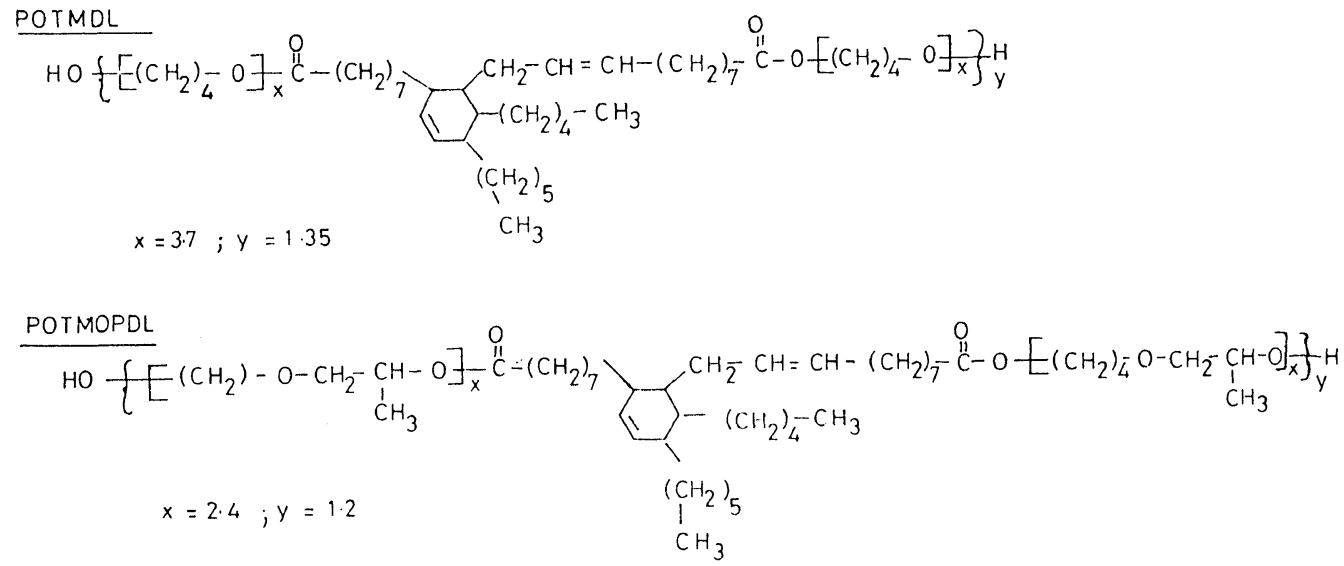

HTPB

$$
\begin{aligned}
& \mathrm{HO}-\left[\mathrm{CH}_{2}-\mathrm{CH}=\mathrm{CH}-\mathrm{CH}_{2}\right]_{x} \mathrm{OH} \\
& x=51.3
\end{aligned}
$$

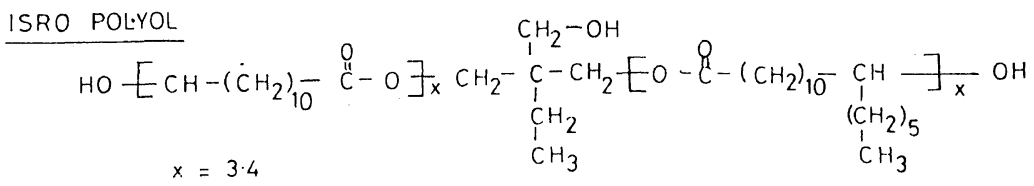

Figure 1. Structure of the dimer acid, crosslinking agents (Castor oil, TMP, and PVA), and Prepolymers.

Table I. Properties of prepolymers

\begin{tabular}{lcccc}
\hline \multicolumn{1}{c}{ Property } & HTPB & ISRO polyol & POTMDL & POTMOPDL \\
\hline Viscosity $\left(\mathrm{cPs}, 25^{\circ} \mathrm{C}\right)$ & 3258 & 2260 & 1990 & 1910 \\
Specific gravity $\left(25^{\circ} \mathrm{C}\right)$ & 0.903 & 0.930 & 0.964 & 0.985 \\
Hydroxyl number & 40.1 & 55.0 & 75.1 & 77.4 \\
Carboxyl number & 0 & 0 & 1.2 & 0.9 \\
Molecular weight & 2800 & 2040 & 1470 & 1433 \\
\hline
\end{tabular}


Polyurethane Elastomers

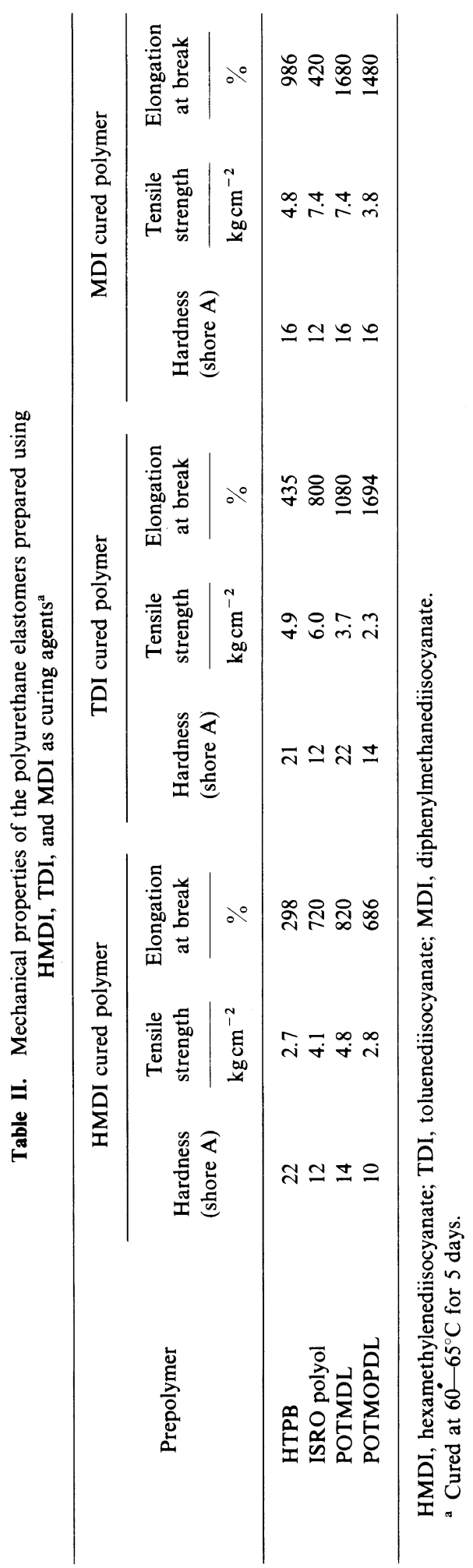


Table III. Effect of castor oil, TMP, and PVA as crosslinking agents on the mechanical properties of HTPB based TDI and HMDI cured polyurethane elastomers

\begin{tabular}{|c|c|c|c|c|c|}
\hline \multirow{2}{*}{$\begin{array}{l}\text { Crosslinking } \\
\text { agent }\end{array}$} & \multirow{2}{*}{ Curing agent $^{\mathrm{a}}$} & \multirow{2}{*}{$\begin{array}{l}\text { Hardness } \\
\text { (shore A) }\end{array}$} & \multirow{2}{*}{$\frac{\text { Tensile strength }}{\mathrm{kg} \mathrm{cm}^{-2}}$} & \multirow{2}{*}{$\frac{\text { Elongation at break }}{\%}$} & \multirow{2}{*}{$\frac{\text { Modulus (initial) }}{\mathrm{kg} \mathrm{cm}^{-2}}$} \\
\hline & & & & & \\
\hline - & HMDI & 22 & 2.7 & 298 & 6.8 \\
\hline- & TDI & 21 & 2.3 & 480 & 20.7 \\
\hline Castor oil & HMDI & 32 & 5.2 & 242 & 43.7 \\
\hline Castor oil & TDI & 32 & 5.6 & 311 & 41.0 \\
\hline TMP & HMDI & 34 & 8.9 & 243 & 39.8 \\
\hline TMP & TDI & 46 & 10.2 & 218 & 42.1 \\
\hline PVA & HMDI & 40 & 9.1 & 223 & 33.6 \\
\hline PVA & TDI & 38 & 9.8 & 192 & 50.7 \\
\hline
\end{tabular}

$[\mathrm{OH}$ of $\mathrm{HTPB}] /[\mathrm{OH}$ of crosslinking agent $]=0.5$; $[$ Total $\mathrm{OH}] /[\mathrm{NCO}]=1$.

${ }^{\text {a }}$ Cured at $80^{\circ} \mathrm{C}$ for 5 days.

Table IV. Effect of TMP concentration on mechanical properties of HTPB, ISRO polyol, POTMDL, and POTMOPDL based TDI cured polyurethane elastomers ${ }^{\mathrm{a}}$

\begin{tabular}{|c|c|c|c|c|c|c|c|c|}
\hline \multirow{3}{*}{$\frac{\text { TMP }[\mathrm{OH}]}{\text { Prepolymer }[\mathrm{OH}]}$} & \multicolumn{2}{|c|}{$\begin{array}{l}\text { HTPB-TDI } \\
\text { polymer }\end{array}$} & \multicolumn{2}{|c|}{$\begin{array}{l}\text { ISRO polyol-TDI } \\
\text { polymer }\end{array}$} & \multicolumn{2}{|c|}{$\begin{array}{l}\text { POTMDL-TDI } \\
\text { polymer }\end{array}$} & \multicolumn{2}{|c|}{$\begin{array}{l}\text { POTMOPDL-TDI } \\
\text { polymer }\end{array}$} \\
\hline & Hardness & $\begin{array}{c}\text { Tensile } \\
\text { strength }\end{array}$ & Hardness & $\begin{array}{c}\text { Tensile } \\
\text { strength }\end{array}$ & Hardness & $\begin{array}{l}\text { Tensile } \\
\text { strength }\end{array}$ & Hardness & $\begin{array}{l}\text { Tensile } \\
\text { strength }\end{array}$ \\
\hline & & $\mathrm{kgcm}^{-2}$ & & $\mathrm{kgcm}^{-2}$ & & $\mathrm{~kg} \mathrm{~cm}^{-2}$ & & $\mathrm{~kg} \mathrm{~cm}^{-2}$ \\
\hline 0 & 20 & 2.3 & 12 & 8.0 & 22 & 3.7 & 14 & 2.3 \\
\hline 0.2 & 28 & 3.8 & 18 & 8.3 & 30 & 6.5 & 18 & 3.9 \\
\hline 0.3 & 36 & 5.1 & 19 & 11.2 & 32 & 7.4 & 20 & 8.1 \\
\hline 0.4 & 44 & 8.4 & 21 & 13.1 & 36 & 8.8 & 28 & 12.9 \\
\hline 0.5 & 46 & 10.2 & 24 & 18.3 & 42 & 14.1 & 28 & 14.8 \\
\hline 0.6 & 50 & 13.9 & 28 & 18.4 & 48 & 18.9 & 32 & 18.4 \\
\hline
\end{tabular}

$[$ Total $\mathrm{OH}] /[\mathrm{NCO}]=1$.

a Cured at $80^{\circ} \mathrm{C}$ for 5 days.

varying the amount of TMP as the ratio of hydroxyl content of TMP to that of the prepolymer ranging from 0 to 0.6 . In all these cases, the hardness and tensile strength increased with an increase in TMP content as expected. Except POTMOPDL, in all other systems elongation increased first, reached a maximum at a particular TMP content, and then decreased further (Figure 2). This suggests that in these soft polyurethane systems (having low tensile strength) sufficient strength of the material to possess better elongation is attained with a certain percentage of crosslinking only. The crosslinking in polyurethane can also be induced by preparing it with higher [NCO]/ $[\mathrm{OH}]$ ratio ( $R$ value greater than 1$)$ and at high temperature curing. Crosslinking at higher $R$ value is reported to proceed through the formation of allophanate and isocyanurate linkages. $^{7}$ Allophanate groups are formed from isocyanate and urethane group (eq 1) and isocyanurate group as the result of trimerization of the isocyanate (eq 2) which is also called the isocyanurate trimer. Allophanate 


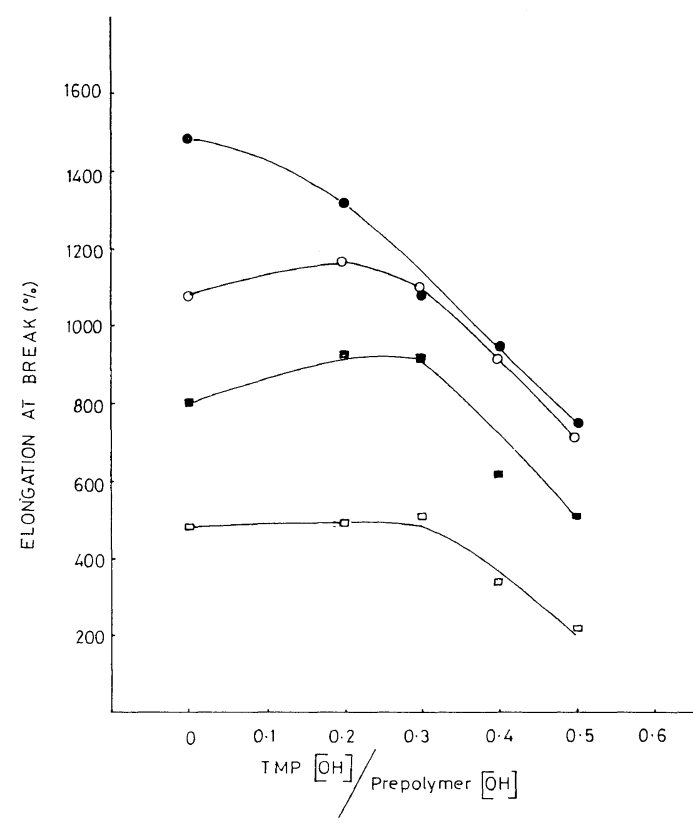

Figure 2. Effect of TMP concentration on elongation at break of TDI cured polyurethane elastomers based on prepolymers: (O) POTMDL; (○) POTMOPDL; ( $\square$ ) HTPB; (ם) ISRO polyol.

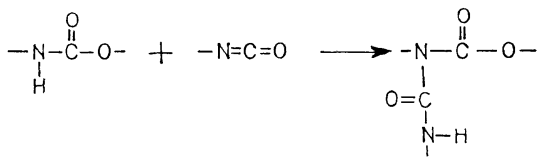

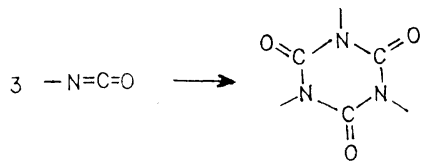

formation is the favorable reaction in the uncatalysed reaction system, whereas trimerization of isocyanate is favoured under basic catalyst. ${ }^{24}$ It is difficult to have a quantitative data on the degree of crosslinking by allophanate group in competition with the other side reactions at higher $R$ values. As the present system did not involve any catalyst, the crosslinking occurred at higher $R$ value might have been due to the allophanate linkage which was confirmed by IR method at $1740 \mathrm{~cm}^{-1}$. The tensile strength and hardness increased considerably on increasing of the $R$ value (Table $\mathrm{V}$ ). The observation of

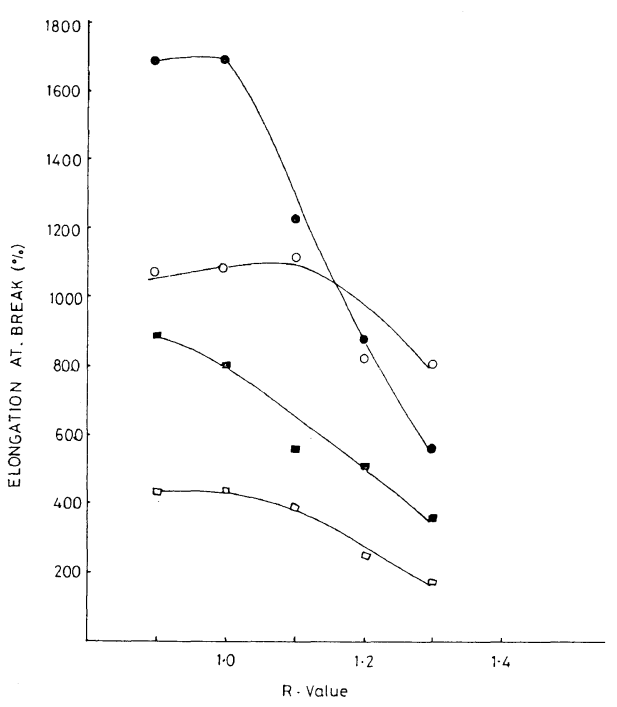

Figure 3. Effect of $R$ value on elongation at break of TDI cured polyurethane elastomers based on prepolymers: (O) POTMDL; (O) POTMOPDL; ( $\square$ ) HTPB;

(ם) ISRO polyol.

maximum elongation at the $R$ value 1.0 was observed in case of HTPB based polyurethane, whereas continuous decrease in elongation was observed from the $R$ value 0.9 in case of ISRO Polyol-TDI system (Figure 3). HTPB can form linear structure of maximum molecular weight at the $R$ value of unity which is also confirmed by its viscosity values $\left(\eta_{\text {inh }}\right)$ (Table V). Crosslinked product was formed at $R$ value greater than 1.0 and the polymer was insoluble. The continuous drop in elongation from the $R$ value 0.9 , in case of ISRO PolyolTDI based polyurethane is due to the trifunctionality of ISRO polyol which leads to the crosslinked polyurethane even below the $R$ value of 1.0. Similar to that of HTPB-TDI system, POTMOPDL-TDI based polyurethane showed maximum elongation at the $R$ value of 1.0, whereas POTMDL-TDI system showed comparable elongation values in the $R$ values ranges from 0.9 to 1.1 . In all these polyurethanes the crosslinking induced by excess diisocyanate behaves in a different way on elongation compared to that obtained through TMP. The elongation maximum was observed 
H. Kothandaraman, K. Venkatarao, and B. C. Thanoo

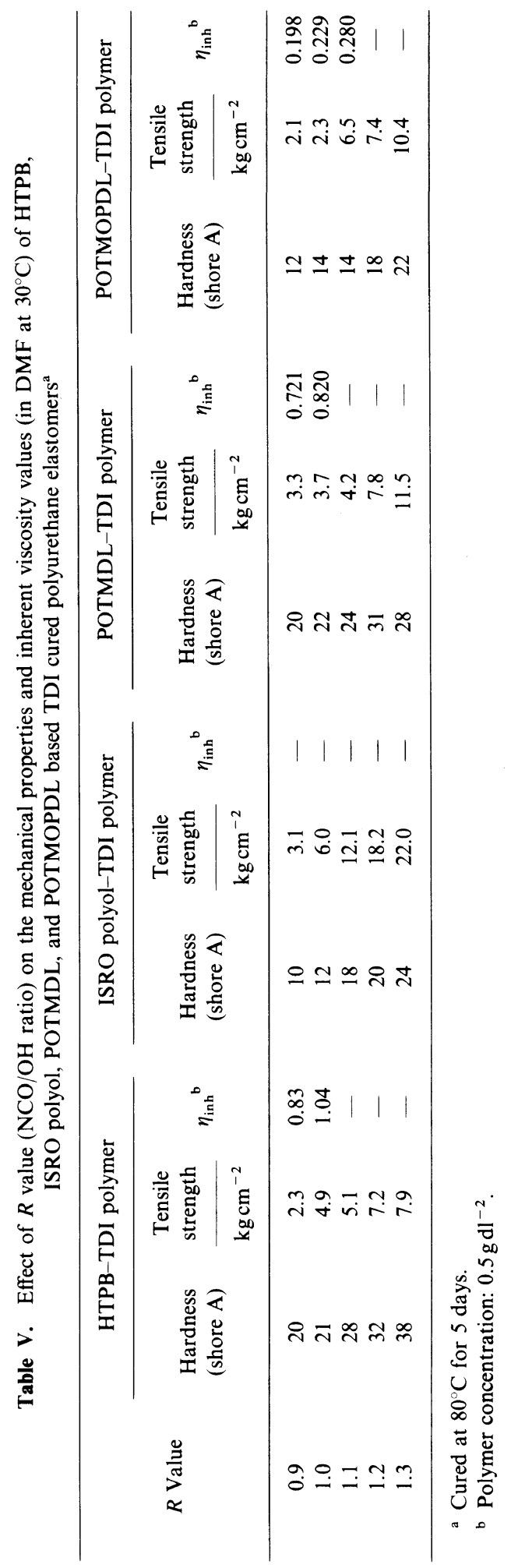




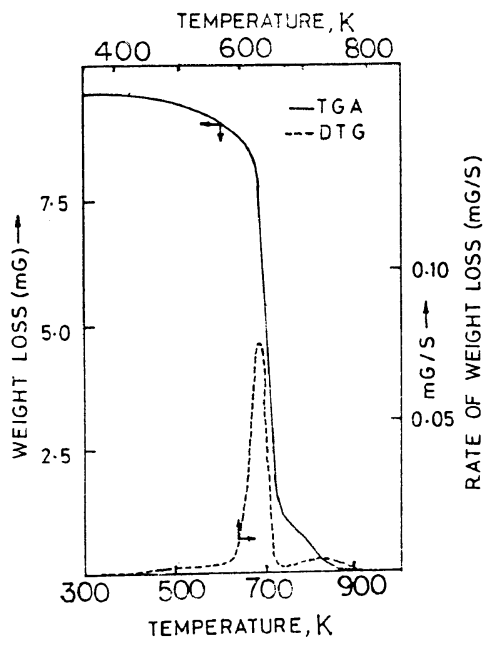

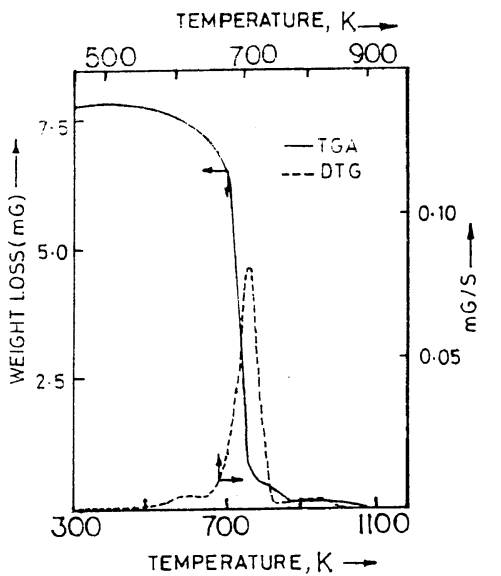

(b)

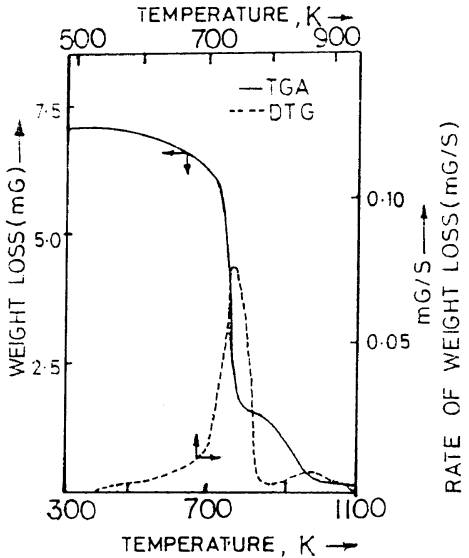

(c)

Figure 4. TGA and its derivative (DTG) curves of polyurethanes: (a) HTPB-HMDI; (b) HTPB-TDI; (c) HTPB-MDI.

with certain percentage of crosslinking by TMP where as the crosslinking induced in polyurethane by excess diisocyanate in general faces continuous drop in elongation (Figures 2 and 3). But both the methods of crosslinking behaves in a similar way on improving the hardness and tensile strength of the polyurethane.

Thermal degradation (TGA analysis) of the representative polyurethanes was carried out in an oxygen atmosphere. Thermal oxidative degradation is more complex than simple ther- mal degradation because of crosslinking ${ }^{25}$ and oxygen absorption ${ }^{26}$ in the initial decomposition stages. The degradation of all polyurethanes proceeds in two stages (Figures 4 and 5). The first stage of decomposition is the major process and nearly $80-90 \%$ of the polyurethane starts decomposing at $475 \mathrm{~K}$ land continued upto $800 \mathrm{~K}$ (Table VI). The second step can only be the oxidation of the residual material (combustion) since the degradation was carried out in the atmosphere of oxygen. The effect of the structure of the 


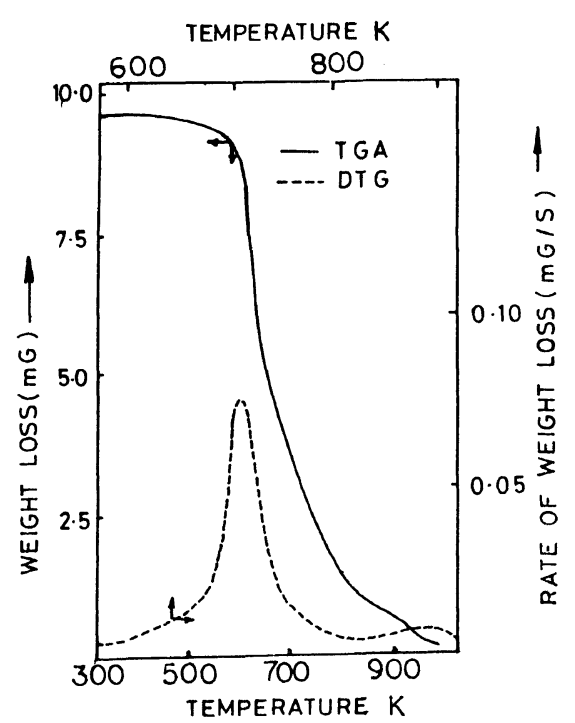

(a)

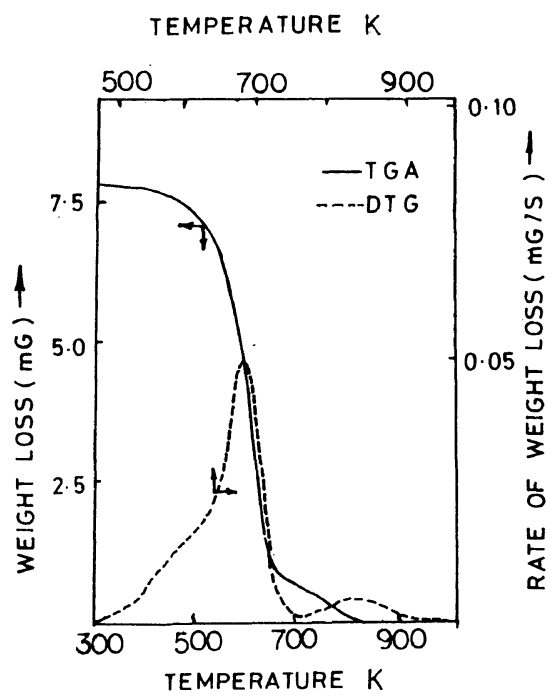

(b)

Figure 5. TGA and its derivative (DTG) curves of polyurethanes (a) ISRO polyol-TDI and (b) POTMOPDL-TDI.

Table VI. Degradation stages of HTPB, ISRO polyol, and POTMOPDL based polyurethanes and the characteristic temperature with weight loss

\begin{tabular}{|c|c|c|c|c|c|c|}
\hline \multirow{3}{*}{ Polymer } & \multicolumn{3}{|c|}{ First stage decomposition } & \multicolumn{3}{|c|}{ Second stage decomposition } \\
\hline & Temperature range & $T_{\max }$ & Weight loss & Temperature range & $T_{\max }$ & Weight loss \\
\hline & K & K & $\%$ & $\mathrm{~K}$ & K & $\%$ \\
\hline HTPB-HMDI & $475-765$ & 735.0 & 89.0 & $765-941$ & 819 & 9.8 \\
\hline HTPB-MDI & $478-778$ & 738.0 & 86.6 & $788-973$ & 848 & 10.6 \\
\hline HTPB-TDI & $486-784$ & 740.3 & 90.5 & $784-935$ & 831 & 8.4 \\
\hline ISRO polyol-TDI & $500-801$ & 742.0 & 89.6 & $801-973$ & 882 & 8.2 \\
\hline POTMOPDL-TDI & $476-752$ & 673.3 & 89.4 & $752-968$ & 828 & 10.5 \\
\hline
\end{tabular}

diisocyanate on thermal degradation of polyurethane has been brought out by various groups. $^{27,28}$ In the present investigation, the type of diisocyanate is not having much influencle on the degradation pattern. The structural contribution of the prepolymer segments to the thermal degradation can be expected to be more compared to the diisocyanate part due to its higher content in the polyurethane. Increase in the saturated aliphatic content has been reported to increase the thermal stability. ${ }^{29}$ ISRO polyol based polyurethane having more saturated aliphatic content is more resistant towards oxidative degradation compared to that of HTPB based system (Table VI). The first stage degradation of HTPB-TDI polyurethane started at $486 \mathrm{~K}$ while that of ISRO polyol based one started only at $500 \mathrm{~K}$. POTMOPDL-TDI showed first stage decomposition at a comparatively lower temperature than that of HTPB and ISRO polyol based systems due to the less thermally stable ether groups present in excess. 


\section{CONCLUSIONS}

Polyurethanes produced from all the four prepolymers in a one shot process without chain extender are soft elastomers having low tensile strength. Crosslinking either by the introduction of a triol or by excess diisocyanate plays a major role in improving the hardness and tensile strength of these elastomers. A unique observation on elongation was observed with a crosslinking by a triol (TMP), where the elongation (at break) increased first with the increase in concentration of TMP and after reaching a maximum started decreasing, whereas crosslinking induced by excess diisocyanate resulted in a continuous decrease of elongation. Thermal stability of the ISRO polyol based polyurethane is more than that of HTPB based one and relatively lower thermal stability was observed in case of polyether-dimer acid based polyurethane systems.

Acknowledgements. Department of Science and Technology, New Delhi (India) is gratefully acknowledged for the financial support and the award of fellowship for one of the authors (B.C.T). The authors thank Dr. V. N. Krishnamoorthy, VSSC, Trivandrum, India for his help during this work.

\section{REFERENCES}

1. J. H. Saunders, J. A. Burronghs, and L. P. Williams, J. Appl. Polym. Sci., 19, 1387 (1975).

2. R. Bonart, Morbitzer Kolloid. Z.-Z. Polym., 241, 909 (1970).

3. W. J. Murbach and A. Adicoff, Ind. Eng. Chem., 52, 772 (1960).

4. E. Windemuth, Kunststoffe, 57, 337 (1967).

5. T. Yokoyama and M. Furukawa, "International Progress in Urethanes," Vol. 2, Technomic, Westport, Conn., 1976, p 125.
6. D. Irena and K. Danuta, Polimery (Warsaw), 26, 257 (1981).

7. J. H. Saunders and K. C. Frisch, "PolyurethaneChemistry and Technology," Part I, Chemistry, Interscience Publishers, New York, 1961, pp 70-72.

8. D. D. Rudolph and K. M. Ashok, Am. Chem. Soc., Div. Org. Coat. Plast. Chem. Pap., 35, 264.

9. S. L. Axelrood, C. W. Hamilton, and K. C. Frish, Ind. Eng. Chem., 53, 889 (1961).

10. E. C. Haag, K. A. Pigott, and J. H. Saunders, Paper presented to ACS meeting, Div. of Rubber Chemistry, Montreal, 1967.

11. S. Akihisa, Japan Kokai, 75126799 (1975) [Chem. Abstr., 94, 60263g (1976)].

12. A. D. Yates, W. T. J. Morgan, and M. W. Winifred, FEBS Lett., 60, 281 (1975).

13. L. A. Dickinson, J. Polym. Sci., 58, 857 (1962).

14. D. Brown, H. Cherdron, and W. Kern, "Techniques of Polymer Synthesis and Characterization," WileyIntersciences, New York, N. Y., 1963, p 206.

15. F. D. Snell and L. S. Ettre, "Encyclopaedia of Industrial Chemical Analysis," Vol. 18, John Wiley \& Sons, New York, N. Y., 1984, p 184.

16. D. J. David and H. B. Staley, "Analytical Chemistry of the Polyurethanes," Vol. XVI, Part III, WileyIntersciences, New York, N. Y., 1969, pp 357-359.

17. J. S. Fritz and G. H. Schenk, Anal. Chem., 31, 1808 (1959).

18. E. N. Doyle, "The Development and Use of Polyurethane Products," McGraw-Hill Book Company, New York, N. Y., 1971, p 9.

19. ASTM 412 and ASTM 676.

20. W. Cooper, R. W. Pearson, and Darke, Ind. Chemists, 36, 121 (1969).

21. C. W. Bunn, J. Polym. Sci., 16, 323 (1955).

22. E. F. Cluff and E. K. Gladding, J. Appl. Polym. Sci., 3, 290 (1960).

23. J. H. Saunders and K. C. Frisch, "Polyurethanes Chemistry and Technology, Part I. Chemistry," Interscience Publishers, New York, N. Y., 1965, p 50.

24. A. Michael, Ber., 38, 22 (1905).

25. A. Koscielecka, Polimery (Warsaw), 20, 537 (1975).

26. Y. A. Orlov and O. G. Tarakanov, Plast. Massy, 42 (1967).

27. Y. Norimichi, Kiyo, 16, 105 (1980).

28. N. P. Kurgan, A. A. Kachan, N. V. Kulik, G. F. Goncharenko, and L. N. Korsakova, Sin. Fiz. Khim. Poliurethanes, 112 (1967).

29. O. G. Tarakanov and V. A. Orlov, Plast. Massy, 37 (1966). 